\title{
La provincia y la diputación. Antecedentes, configuración constitucional y algunos argumentos a favor $y$ en contra de su permanencia
}

\author{
F. Javier Díaz Revorio \\ Prof. Titular de Derecho Constitucional \\ Enrique Belda Pérez Pedrero \\ Prof. Dr. Asociado de Derecho Constitucional \\ (Universidad de Castilla-La Mancha) ${ }^{1}$
}

Sumario: 1. INTRODUCCIÓN HISTÓRICA. 2. LA PROVINCIA EN LA CONSTITUCIÓN ESPAÑOLA DE 1978. 3. LA GARANTÍA CONSTITUCIONAL DE LA AUTONOMIAA PROVINCIAL. 4. AUTONOMÍA PROVINCIAL, AUTONOMÍA DE NACIONALIDADES Y REGIONES, Y AUTONOMÍA MUNICIPAL. 5. RAZONES A FAVOR DEL MANTENIMIENTO DE LA PROVINCIA Y DE SU INSTITUCIÓN REPRESENTATIVA. 6. ARGUMENTOS CONTRA LA NECESIDAD DE LA PROVINCIA COMO ENTIDAD LOCAL.

\section{INTRODUCCIÓN HISTÓRICA}

La provincia como división territorial del Estado en el sentido moderno de su acepción, y con una administración, la diputación, a su frente, nace para el gobierno de las provincias con la Constitución de 1812 aunque su establecimiento efectivo se produce durante el trienio liberal (1820-23) y a partir de 1833, por impulso de un alto funcionario de María Cristina de Borbón, llamado Javier de Burgos. Los años que siguen a la Guerra de la Independencia son esenciales en la configuración de lo que entendemos en la actualidad por provincia, y de su órgano de gobierno, la

\footnotetext{
1 Este trabajo es obra común de sus dos autores. La redacción original de los puntos 1,2 , y 5 corresponde a Enrique Belda, mientras que la de los puntos 3 y 6 ha corrido a cargo de F. Javier Díaz Revorio, y la del punto 4 a cargo de ambos autores; aunque se ha revisado conjuntamente todo el texto, hasta llegar a su versión definitiva. Los autores comparten en esencia todos los argumentos expresados en los puntos 1 a 4 sobre los antecedentes históricos y la configuración constitucional de la provincia. Sin embargo, mantienen posiciones no coincidentes sobre la necesidad o conveniencia de la entidad local, que en esencia aparecen resumidas en los puntos 5 (argumentos a favor) y 6 (argumentos en contra, a los que lógicamente se dedica mayor extensión, dado que implican la justificación de una reforma constitucional); aunque desde luego parte de los argumentos en uno y otro sentido son asumidos por ambos. En definitiva, el trabajo trata de poner de manifiesto que, compartiendo una misma base desde el punto la perspectiva histórica y constitucional, existen distintas visiones sobre el significado y utilidad de la institución provincial en la actualidad.
} 
Diputación. En esos tiempos se pensará en esta circunscripción como elemento territorial vertebrador de la nación, que reafirma lo estatal frente al pouvoir municipal (BOIX REIG: 1988, p. 345) y controla la posible fuerza de los municipios constitucionales.

Las Cortes de Cádiz, reunidas en septiembre de 1810, tuvieron que reordenar la caótica situación de un país en guerra. Tras unos meses de trabajo realizaron un primer agrupamiento provincial mediante un reglamento transitorio, el Decreto provisional para el Gobierno de las Juntas de Provincia de 18 de marzo de 1811 . Se estudia la necesidad de un órgano de gobierno provincial, a modo del existente en algunos territorios históricos (SANTANA MOLINA: 1989, p. 276) y como continuación de las juntas que surgen en la invasión. A pesar de ello, el sustrato organizativo es más parecido al francés y a su organización de consejos departamentales. La provincia como división era esencial como pieza organizativa estatal y circunscripción a efectos electorales, judiciales y administrativos: "(...) marco de integración de las representaciones sociales del territorio, a efectos de participación en los problemas del gobierno del mismo (...)» (MORELl OCAÑA: 1988, p. 659). El artículo 11 de la Constitución efectúa la división en base a las ciudades de nombre más conocido. El Decreto de 23 de mayo de $1812^{2}$ marca una división territorial en diecinueve provincias (que aumentarán a cincuenta y dos tras las Cortes de marzo de 1820). Esta división es parecida a la que lustros antes realizara Floridablanca; y sitúa en su cabeza administrativa a la Diputación.

La aparición histórica de la nueva institución requiere varias precisiones acerca de su organización y naturaleza. No todas las provincias tenían diputación y en ocasiones una administración provincial podía gobernar sobre varios territorios. Se reúnen en períodos de sesiones que no superen los noventa días al año (art. 334 de la Constitución de Cádiz), y los asuntos urgentes se despachan en comisiones o por el jefe político. Su mayor período de actividad coincidía con la existencia de gobiernos centrales más liberales, que a lo largo del siglo recuperaron ciertas ideas autonomistas, mientras que los gobiernos conservadores y moderados la dotaban de un mero carácter consultivo y la preeminencia del jefe político se acentuaba. En cualquier caso, la trayectoria de la institución muestra que irá asumiendo competencias progresivamente dentro de la pugna entre centralización y descentralización de las décadas siguientes.

2 Decreto CLXIV sobre establecimiento de las Diputaciones provinciales en la Peninsula y Ultramar, que es trascendental en el nacimiento de la diputación. Se puede consultar en T. R. FERNÁNDEZ Rodriguez y J. A. SANTAMaría PAStor, Legislación administrativa española en el siglo XIX. Madrid, 1977. 
En cuanto a su naturaieza, descansaba sobre los principios de electividad, uniformidad (con las excepciones de las Juntas del País Vasco, que permanecían fuera del proceso) y jerarquía y subordinación, respecto del poder central, que podía disolverlas a la menor discrepancia. Se trataba en todo caso de órganos consultivos y deliberantes pero nunca representativos. Al respecto ORDUÑa recuerda que algunos políticos de la época trataron de compatibilizar el principio de representación nacional única de las Cortes con la representatividad de las diputaciones (Alcocer y Leiva) (ORDUÑa REBOLlO: 1998, p. 48).

Igual que sucede con los municipios, el de 1812 es el único texto constitucional que en su articulado (los demás textos dejarán a la ley esa cuestión) refleja un régimen electoral provincial: a) la dirección política de la provincia corresponde al jefe político-gefe superior-nombrado por el Rey (art. 324). Por tanto, no es órgano de la nueva institución local sino del Estado, inserto en la primera como presidente (art. 325). En la práctica preside sólo el ayuntamiento de la capital de la provincia, aunque en teoría fuese presidente de todos los municipios. b) Composición. Además del gefe, se elige un intendente (que preside la diputación en ausencia del gefe superior, y si falta, el vocal que fue primer nombrado) y 7 individuos, si bien la ley puede variar este número (hasta 1868 , el número variará de 7 a 9 y con la Restauración, de 20 a 25). c) Mandato. Cuatro años, renovándose por mitades cada dos. d) Votación. Indirecta, de tercer grado. Los electores de partido reunidos en las juntas provinciales han sido previamente elegidos con la misión de nombrar los cargos provinciales y tres suplentes [también y principalmente para elegir los diputados a Cortes; cosa que hacen un día antes (arts. 328 y 329)]. Los electores provinciales provienen de los electores de parroquia, que a su vez fueron escogidos por los vecinos (ver figura). e) Sufragio pasivo. Es necesario ser ciudadano en el ejercicio de derechos, mayor de 25 años, con capacidad económica para mantenerse y vecino de la provincia con residencia por un período no inferior a siete años. f) Inelegibilidades e incompatibilidades. No cabe presentarse a la reelección consecutiva, es necesario aguardar un mandato. Son incompatibles los cargos de elección con los empleados del Rey.

Este nuevo orden se suprime por decreto de Fernando VII de 15 de junio de 1814 que acaba con las diputaciones. La situación de suspensión se prolongó hasta el pronunciamiento de Riego. Concepción DE CASTRO relata que las elecciones provinciales de 1812 y años sucesivos fueron un modelo de regularidad y normalidad frente a los conflictos municipales que eran muchos: sólo hubo que resolver un conflicto en la elección de la 
REALA 284 (SEPTIEMBRE-DICIEMBRE, 2000)

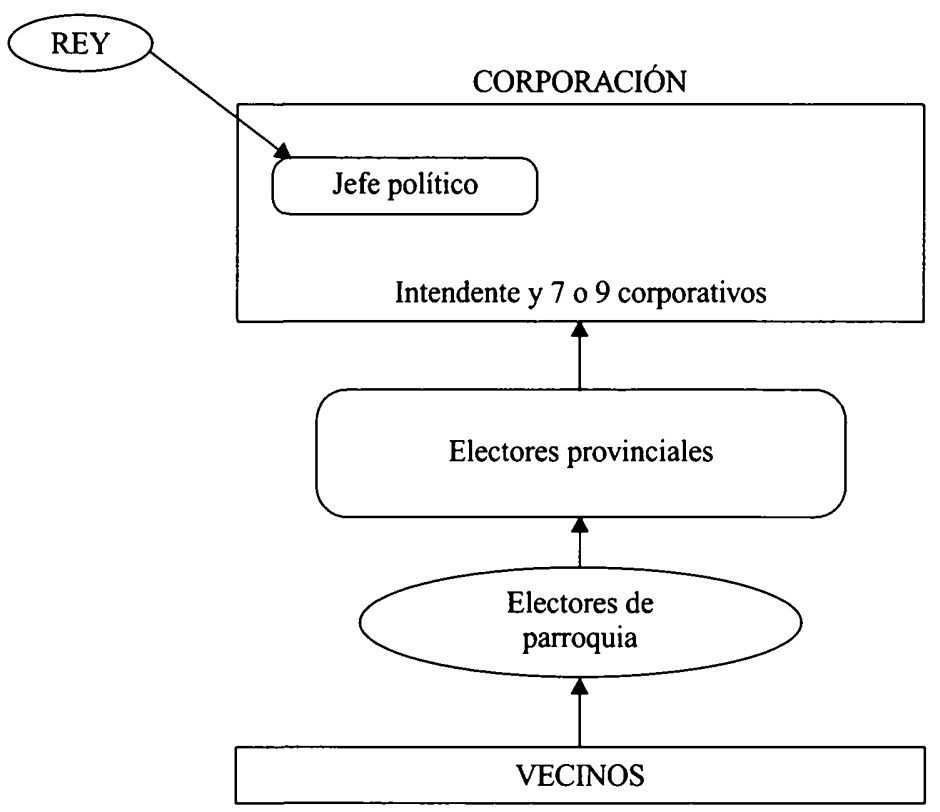

diputación de Extremadura en el año 1813. El complemento normativo del texto constitucional fue la Instrucción para el gobierno de las provincias de 23 de junio de 1813; y más tarde, en el trienio liberal la Instrucción de 2 de marzo de 1823.

Los territorios provinciales, tras su surgimiento en 1812, sufren algún cambio hasta la división provincial de 1833, pero entre las dos fechas se configura un mapa que prácticamente llega a nuestros días. La más importante modificación es la que se proyectaba por las Cortes de marzo de 1820 , en el decreto LIX de 27 de enero de 1822 , que contenía 52 provincias y es el antecedente del RD de 30 de noviembre de 1833, obra de Javier de Burgos.

La diputación, impulsada desde la Constitución, se implanta uniformemente, con la excepción del País Vasco y Navarra (a lo largo de las décadas siguientes se produce la integración de las diputaciones de Navarra, en 1839 , y de las provincias vascas en 1841 , por decreto de Espartero de 29 de octubre, aunque no renunciarán a buena parte de sus señas identificativas y, sobre todo, de sus competencias). La inserción en la estructura jerárquica del Estado condiciona su autonomía respecto al gobierno de turno. A pesar de ello, en este período se comienza a configurar su personalidad jurídica y los rasgos de una administración corporativa dedicada a los intereses propios de la provincia. En el ámbito normativo no se pue- 
de hablar de muchos avances: el decreto de 3 de febrero de 1823 sobre gobierno económico-político de las provincias, con vocación innovadora y ánimo de incrementar la participación, es prácticamente inaplicado por los hechos históricos de ese año que concluyen con la intervención de los Cien Mil hijos de San Luis.

La organización provincial que nace en estos años y que con modificaciones llegará a nuestros días, si bien tiene un indudable germen común con Francia, adquiere una impronta propia que la acaba haciendo muy distinta. Incluso en temas como la determinación de los límites provinciales se han seguido criterios absolutamente contrarios (S. MARTíNRETORTILLO: 1991, pp. 48 y 52).

La idea de los gobiernos centrales durante el siglo pasado, tanto conservadores como liberales, era vigilar los ayuntamientos, especialmente durante los períodos de más funcionamiento de éstos (1812-14, 1820-23, $1837-45,1875-)$. Por ello suele coincidir la presidencia de la corporación provincial con la del jefe político o gobernador civil y son abundantes los ejemplos de intervención legal en los nombramientos.

Los caracteres de la institución representativa y de administración que permanece al frente de la provincia, la diputación, se perfilan en sucesivos momentos históricos hasta nuestros días, si bien no vamos a detallar este proceso por razones de espacio, como hemos hecho respecto a la Constitución gaditana. Apuntar sólo que nosotros destacaríamos tres periodos fundamentales especialmente en los aspectos organizativos: el sexenio revolucionario (1868-1874), los gobiernos de Alfonso XIII de principios del siglo XX (en particular los de Maura), y por último la etapa del Estatuto Provincial de Calvo Sotelo, tras 1925. Estos caracteres son:

— un órgano asambleario de carácter más o menos representativo;

— un órgano unipersonal, que la preside;

— un aparato administrativo;

- una organización complementaria variable (comisiones de estudio).

El componente político representativo se difumina desde comienzos del siglo XX (1907), y durante las dictaduras (1923-29; 1936-75), para recuperarse en nuestros días. 


\section{LA PROVINCIA EN LA CONSTITUCIÓN ESPAÑOLA DE 1978}

El esquema territorial local de la Constitución se edifica sobre dos pilares: el municipio y la provincia «(...) elementos arquitecturados indispensables del orden constitucional» (STC 32/81, F. J. 5, caso Diputaciones catalanas), aunque existan otros territorios dignos de la mención constitucional.

En cuanto a la provincia, tiene una doble dimensión constitucional (art. $141 \mathrm{CE})$ :

a) por un lado, es una división territorial para el cumplimiento de los fines del Estado. Entre ellos, hay que destacar su función como circunscripción electoral en el Congreso (art. 68.2), y en el Senado (art. 69.2), con la excepción, en este último caso, de las provincias insulares, en las que la circunscripción será la isla (art. 69.3). Aunque no está constitucionalmente previsto, nada impide que la provincia actúe también como división territorial para el cumplimiento de los fines de la Comunidad Autónoma, así como circunscripción electoral en este ámbito;

b) es una entidad local, dotada de autonomía para la gestión de sus intereses (art. 137). Como tal entidad local viene determinada por la agrupación de municipios, tiene personalidad jurídica propia y es administrada y gestionada autónomamente por una corporación representativa. En las islas, la institución y administración supramunicipal se denomina cabildo (Canarias) o consejo (Baleares).

Sin perjuicio de lo que más adelante veremos, podemos ahora apuntar los caracteres más fundamentales de la autonomía provincial:

1. Se trata de un ente con múltiples facultades constitucionales y legales. Destacaríamos:

a) La posibilidad de gestionar los asuntos que afecten a la provincia, ejercitando una serie de competencias conferidas por la Ley de Bases de Régimen Local y la legislación de desarrollo, a través de la diputación.

b) La posibilidad de opinar y conocer sobre/en temas que le afecten, igualmente a través de su institución representativa.

c) La posibilidad de disponer de unos recursos suficientes para sus funciones y competencias (142 CE). 
2. Está cubierta como institución por una garantía constitucional, como veremos con más detalle un poco más adelante.

El Tribunal Constitucional afirma que el núcleo de la actividad de la provincia, a través de su diputación, es el apoyo a los municipios de su territorio, mediante una actividad de cooperación económica, financiera y prestacional... La actividad de cooperación es el eje o centro de la autonomía provincial, que no puede ser menoscabado por el legislador (STC 109/98, F. J. 2, caso Plan Único de Obras y Servicios de Cataluña). Estas consideraciones son extensivas a las islas. S. MARTÍN-RETORTILLO, que ha tratado en concreto el tema de la autonomía provincial, nos sugiere también algunos contenidos prácticos de esta autonomía provincial: conseguir y procurar directamente la plena efectividad de las competencias municipales y prestar y asegurar los servicios locales que excedan del municipio (MARTíN-RETORTILLO: 1991, pp. 93 ss. y 110).

Conviene destacar, por último, una importante peculiaridad en el régimen provincial, derivada del desarrollo de las previsiones constitucionales. La generalización del acceso de nacionalidades y regiones al derecho a la autonomía constitucionalmente previsto (y la consiguiente generalización del mapa autonómico), y más en concreto la existencia de ciertas provincias con «entidad regional histórica» $(143.1 \mathrm{CE})$, y de otras que, sin tener tal entidad, fueron autorizadas por las Cortes [art. 144 a) CE], provocó la desaparición de algunos entes locales provinciales. Como es sabido, en virtud del artículo 9 de la Ley del Proceso Autonómico, los órganos y competencias provinciales son «absorbidos» por la Comunidad Autónoma, evitándose así una innecesaria duplicación de órganos sobre idéntico ámbito territorial. Algunos autores se preguntaron a principios de los ochenta sobre la situación de la administración local provincial en las Comunidades Autónomas uniprovinciales: por un lado, se habló de su necesaria continuidad, otros de su transmutación, otros simplemente de su desaparición. El Tribunal Constitucional en la Sentencia sobre las diputaciones de Cataluña, 32/1981 de 28 de julio, F. J. 3, señalaba que la provincia se erige en Comunidad Autónoma. Hoy se puede afirmar que en estas Comunidades Autónomas uniprovinciales la provincia existe sólo como división territorial del Estado y para ciertos fines, como el ser circunscripción territorial para la elección del Congreso o el Senado. Desde luego, su órgano de gobierno es sustituido por el de la Comunidad Autónoma, que asume y amplía sus funciones. En ningún caso se puede hablar de ente local ${ }^{3}$, de potestad autoorganizativa o de autonomía en el

\footnotetext{
${ }^{3}$ La idea que señalamos es contraria a otras expuestas, por ejemplo por A. FonTÁN Pérez, «La experiencia española (Informe sobre la democracia y las CCAA preparado para la UNESCO en
} 
sentido que más tarde describiremos; por contra, se tratará de una potestad de autogobierno y una autonomía política que no encuentra claras referencias anteriores en las atribuciones de la corporación local. En las Comunidades uniprovinciales, los intereses a los que se refiere el $137 \mathrm{CE}$ sólo se encuentran en el nivel municipal y en el de la Comunidad Autóno$\mathrm{ma}$, sin que quepa superponer a los segundos unos intereses provinciales pues abarcarían el mismo contenido y un ámbito territorial coincidente. La excepción a la inexistencia de la dualidad de niveles en la administración local se produce en la Comunidad Autónoma uniprovincial que está compuesta de diversas islas y con base en el artículo 141.4 CE goza de una administración local adicional: Baleares (LOPEZ RODO: 1985, p. 1892).

\section{LA GARANTÍA CONSTITUCIONAL DE LA AUTONOMÍA PROVINCIAL}

Como ya se ha indicado, la autonomía provincial está garantizada constitucionalmente. El artículo 137, tras afirmar que el Estado se organiza territorialmente en municipios, en provincias y en las Comunidades Autónomas que se constituyan, señala que «todas estas entidades gozan de autonomía para la gestión de sus respectivos intereses». Específicamente a la provincia está dedicado el artículo 141.1 que - a diferencia de lo que sucede en el artículo 140 en relación con los municipios- no vuelve a insistir expresamente en su autonomía, señalando, en lo que ahora interesa, que «la provincia es una entidad local con personalidad jurídica propia, determinada por la agrupación de municipios...», y añadiendo que cualquier alteración de sus límites requiere ley orgánica. En fin, el artículo 141.2 sí alude a la autonomía en el ámbito provincial, al afirmar que «El gobierno y la administración autónoma de las provincias estarán encomendadas a Diputaciones u otras Corporaciones de carácter representativo».

Por tanto, y a diferencia de la redacción del Anteproyecto constitucional (que dejaba abierta la posibilidad de que se sustituyera la provincia como entidad local por otras agrupaciones de municipios), el texto finalmente aprobado garantiza la autonomía de la provincia como entidad local. Utilizando la expresión procedente de Schmitt, parte de la doctrina ha hablado de que la norma fundamental contiene una garantia institucional

1993)». En Nueva Revista, núm. 38. febrero-marzo de 1995, p. 143. Sugiere que las CCAA uniprovinciales son a la vez gobierno regional y órgano de la administración local como en las otras restantes cuarenta y una provincias. 
de ia autonomía iocai (en este sentido, PAREJo Alfonso: $1981{ }^{4}$ ), que comprendería la garantía institucional de la provincia. La noción de garantía institucional hace referencia, como es sabido, a un reducto en el que la acción del legislador es posible, pero sin que éste disponga de una facultad de disposición total o inmediata, asegurándose asi frente al poder constituido la presencia y actuación de la institución en el ordenamiento del Estado, e impidiéndose su supresión o su alteración ilegítima. Las garantías institucionales protegen instituciones que se presentan en el momento constituyente ya conformadas y bien definidas en sus rasgos característicos.

Sin embargo, también hay quien ha señalado la inadecuación del concepto de "garantía institucional» para referirlo a la autonomía local, ante la «falta de definición y textura de la institución a la que la Constitución se remite» (ESTEVE PARDO: 1991, p. 136); e igualmente se ha señalado su insuficiencia para garantizar la autonomía frente al legislador, al no garantizar un contenido mínimo o normal, un haz de potestades, o un ámbito de actuación exclusiva o preferente (GARCÍA MORILLO: 1998, p. 26). En esta línea, GARCía Roca pone de manifiesto que la autonomía local no se presentaba en el momento constituyente ya conformada y bien definida en sus rasgos característicos, pues «ni el poder constituyente ni su fruto, la Norma Fundamental, podían tener como paradigma del Gobierno local el ente menor que conocieron desprovisto de autonomía, de democracia y de suficiencia de recursos»; por ello este autor encuentra más útil el concepto de «función constitucional» aplicado a la Ley de Bases del Régimen Local, norma perteneciente al bloque de la constitucionalidad a la que corresponde garantizar unas competencias locales de la manera más concreta posible (GARCíA ROCA: 2000, pp. 38 ss.).

En el contexto de este trabajo no podemos entrar en detalle en esta compleja polémica, pero sí cabe señalar que quizá sea más adecuado hablar, como han hecho varios autores, simplemente de «garantía constitucional» de la autonomía local (y, por lo que ahora nos interesa, de la autonomía provincial), en cuanto que la Norma fundamental garantiza efectivamente la existencia de las entidades locales, así como su autonomía, al tiempo que recoge una serie de características, elementos y criterios aplicables a las mismas, que son indisponibles para el legislador, prescin-

\footnotetext{
${ }^{4}$ Más recientemente, pueden verse los argumentos expuestos por este autor en defensa de la idea de "garantía institucional», de la autonomía local, frente a la de "garantía constitucional», en la comunicación presentada al Seminario de Régimen Local organizado por la Diputación de Barcelona, y recogida en J. Garcla MoRILLo, La configuración constitucional de la autonomia local, Marcial Pons/Diputació de Barcelona, Madrid, 1998, pp. 53 ss.
} 
diendo ahora de la idea, imagen o perfiles de estas entidades en el momento constituyente.

En cualquier caso, el Tribunal Constitucional ha afirmado la existencia de una garantía institucional de la autonomía local en la Constitución. Ya en una de sus primeras Sentencias, la 4/1981, de 2 de febrero (caso Ley de Bases del Régimen Local), realizó unas importantes consideraciones sobre el concepto de autonomía y su aplicación en el ámbito local, señalando que el concepto de autonomía hace referencia a un poder limitado, que no puede oponerse al principio de unidad; que la autonomía reconocida a las entidades locales se garantiza para la «gestión de sus respectivos intereses», lo que exige que se dote a cada ente de las competencias que sean necesarias para satisfacer el interés respectivo; y que será la ley la que concrete el principio de autonomía para cada tipo de entes.

Más en concreto, y por lo que se refiere al ámbito provincial, hay que destacar la importante jurisprudencia contenida principalmente en las Sentencias 32/1981, de 28 de julio (caso Diputaciones Catalanas), 27/1987, de 27 de febrero (caso Diputaciones Valencianas) y, más recientemente, 109/1998, de 21 de mayo, caso Plan Único de Obras y Servicios de Cataluña 5 . Sin entrar en su análisis exhaustivo, conviene destacar las ideas esenciales de la misma:

1) La provincia es una entidad local que goza de autonomía para la gestión de sus intereses. «Los artículos 137 y 141 de nuestra Constitución contienen una inequívoca garantía de la autonomía provincial» (STC 32/1981, F. J. 3).

2) La provincia es una de las instituciones que se considera un componente esencial y cuya preservación es indispensable para asegurar los principios constitucionales, estableciéndose así un núcleo o reducto indisponible para el legislador. La provincia es uno de los «elementos arquitecturales indispensables del orden constitucional». El Tribunal Constitucional acude expresamente a la noción de garantía institucional, señalando que la misma «no asegura un contenido concreto o un ámbito competencial determinado y fijado de una vez por todas, sino la preservación de una institución en términos recognoscibles para la ima-

\footnotetext{
${ }^{5}$ Entre las sentencias que se refieren a la autonomía local, y además de las citadas en el texto, pueden destacarse las siguientes: 84/1982, de 23 de diciembre; 38/1983, de 16 de mayo (caso Ley de Elecciones Locales); 76/1983, de 5 de agosto (caso LOAPA); 100/1984, de 8 de noviembre (caso Segovia); 214/1989, de 21 de diciembre (caso Ley de Bases del Régimen Local, II), o 385/1993, de 23 de diciembre.
} 
gen que de la misma tiene la conciencia social en cada tiempo y lugan» (STC 32/1981, F. J. 3).

3) La configuración institucional concreta de la provincia — según aclara el Tribunal Constitucional en la misma sentencia - se defiere por la Constitución al legislador ordinario «al que no se fija más límite que el del reducto indisponible o núcleo esencial de la institución que la Constitución garantiza»; de forma que «la única interdicción claramente discernible es la de la ruptura clara y neta con la imagen comúnmente aceptada de la institución que, en cuanto formación jurídica, viene determinada en buena parte por las normas que en cada momento la regulan y la aplicación que de las mismas se hace».

No obstante, el legislador no se encuentra siempre con los mismos límites, ya que mientras el legislador estatal básico (ex art. 149.1.18. ${ }^{a} \mathrm{CE}$ ) encuentra como único límite la garantía constitucional, el legislador «no básico» ( $\mathrm{y}$, en todo caso, el legislador autonómico) debe respetar también la legislación básica del Estado, siempre que ésta sea respetuosa con el orden constitucional. Por ello es posible una inconstitucionalidad «mediata o indirecta», no derivada de una contradicción frontal con la Constitución, sino de la colisión con un precepto básico, pero en tal caso el Tribunal debe determinar inicialmente si la norma estatal que opera como canon tiene, en efecto, ese carácter básico (STC 109/1998, F. J. 3) ${ }^{6}$. Algún autor ha afirmado que la garantía constitucional de la autonomía local se apoya en un «bloque de la constitucionalidad local» (del que formarían parte la LBRL, los Estatutos de Autonomía, la Carta Europea de Autonomía Local y la Ley de Haciendas Locales), de manera que la autonomía local «no es una autonomía en el marco de la ley, es una autonomía en el marco del bloque de la constitucionalidad» (GARCÍA ROCA, 2000, p. 37).

4) La autonomía provincial se define como el «derecho de la comunidad local a participar, a través de órganos propios, en el gobierno y ges-

\footnotetext{
${ }^{6}$ Con todo, la mencionada sentencia considera que la regulación general establecida en el artículo 36.2 a) LBRL respecto a los planes provinciales de cooperación a las obras y servicios municipales, y el papel de la Comunidad Autónoma como coordinadora de estos planes, no es aplicable en el caso de Cataluña, ya que dicho papel coordinador se reconoce «sin perjuicio de las competencias reconocidas en los Estatutos de Autonomía y de las anteriormente asumidas y ratificadas por éstos». En efecto, el Estatuto catalán (D.T. $6 .^{2}$ ) dispone que la Generalidad asumirá definitiva y automáticamente los servicios ya traspasados, y el R. Decreto $2115 / 1978$, de 26 de julio, había traspasado a la Generalidad la confección y aprobación de un Plan Único de Obras y Servicios para su territorio (art. 2.2). De esta forma, "la referida cláusula "sin perjuicio" permite excepcionar en Cataluña la aplicación del régimen común básico regulador de las relaciones entre las Comunidades Autónomas y las provincias en punto a la cooperación económica con los municipios, que se instrumenta a través de la actividad planificadora», y por lo tanto sólo en Cataluña es posible un Plan Único de Obras y Servicios sustitutivo de los provinciales.
} 
tión de cuantos asuntos le atañen» (STC 32/1981, F. J. 4, ó 27/1987, F. J. 2). Ello implica en definitiva:

a) existencia de órganos propios (representativos);

b) haz mínimo de competencias para atender la gestión de sus intereses;

c) posibilidad de disponer de recursos suficientes para el ejercicio de esas competencias (aspecto éste establecido en el art. 142 para todas las Corporaciones locales).

El problema es la delimitación de ese «haz mínimo» de competencias. Desde luego, el mismo no está especificado en la Constitución, pero puede entenderse que serán aquéllas necesarias para evitar la desaparición de la provincia como entidad local autónoma para la gestión de sus intereses. Con lo que la cuestión de los «intereses propios» o «asuntos propios» se convierte en el punto central para delimitar la garantía constitucional de la autonomía provincial. Como ha destacado EsTEVE PARDo (1991, p. 133), el derecho a participar en el gobierno y administración de los asuntos que le atañen viene a recomponer, en el plano sustantivo, la ausencia en las determinaciones constitucionales de un núcleo competencial mínimo. Y ello porque dicho núcleo mínimo deriva de la propia garantía constitucional de la autonomía "para la gestión de los asuntos que atañen» a la provincia. Más en concreto, y como ya hemos destacado, el Tribunal Constitucional ha afirmado que el núcleo de la actividad de la provincia como entidad local es el apoyo a los municipios radicados en su ámbito territorial, «actividad que se traduce en la cooperación económica a la realización de obras y servicios municipales, y que es llevada a la práctica a través del ejercicio de su capacidad financiera o de gasto público por parte del ente provincial» (STC 109/1998, F. J. 2).

5) La Sentencia de 1981 sobre las diputaciones catalanas afirma expresamente que tanto los intereses propios como el haz mínimo de competencias que de ellos derivan "han de ser inflexionados» para acomodarse a la existencia de otras entidades autónomas de nueva creación. Esta adaptación se produce en relación con dos nuevos ámbitos de poder:

a) En primer lugar, con las Comunidades Autónomas. Dentro de este ámbito, y siguiendo el razonamiento del Tribunal Constitucional, cabe distinguir entre Comunidades Autónomas pluriprovinciales y uniprovinciales. En el primer caso, parte de las competencias que anteriormente fueron provinciales pasarán a ser de la Comunidad, con lo que se reducirá 
el ámbito competencial de la entidad provinciai. En cambio, en eì caso de las Comunidades uniprovinciales, el Tribunal entendió que la autonomía provincial quedaba potenciada, al erigirse la provincia en Comunidad Autónoma, asumiendo así un superior nivel de autonomía (STC 32/1981, F. J. 3); aunque ya hemos apuntado que, desde otra perspectiva, podría entenderse que la provincia (entendida como entidad local) más bien desaparece en este supuesto, asumiendo sus funciones una entidad cuya autonomía es de naturaleza distinta.

b) En segundo lugar, las competencias provinciales han de modularse en atención a la existencia de agrupaciones de municipios diferentes a la provincia (especialmente comarcas), que pueden asumir competencias que en otro caso corresponderían a ésta. Desde luego, la existencia de estas entidades no está constitucionalmente impuesta, sino que es simplemente una posibilidad (art. 141.3 de la Constitución). Y ni siquiera existe una mención constitucional a la autonomía de estas entidades allí donde existan; pero el propio Tribunal Constitucional se ha referido a su «clara vocación autonómica» (STC 32/1981, F. J. 3). En todo caso, nada impide que puedan establecerse, e incluso ser dotadas de autonomía, siempre y cuando no suplanten o hagan desaparecer a la entidad local provincial.

Conviene por tanto insistir en que las competencias de la provincia son en cierto modo «moldeables», pero en ningún caso pueden llegar a desaparecer.

6) Por lo demás, la existencia de diversos entes dotados de autonomía, en el marco de la unidad de la Nación, exige la armonización entre los diversos niveles. Como ha señalado el Tribunal Constitucional, «dado que cada organización territorial dotada de autonomía es una parte del todo, no cabe deducir de la Constitución que, en todo caso, corresponda a cada una de ellas un derecho o facultad que le permita ejercer las competencias que le son propias en régimen de estricta y absoluta separación»" (STC 27/1987, F. J. 2).

Conviene concluir este apartado con algunas consideraciones que pueden plantearse, a la luz de las ideas esenciales que hemos venido señalando. Hay que aclarar que la garantía constitucional de la provincia se refiere a la institución en cuanto tal y no a la concreta denominación, capitalidad y límites territoriales de cada una de las provincias. En cuanto a este último aspecto, hay que recordar que el artículo 141.1 de la Constitución señala que «la alteración de los límites provinciales habrá de ser aprobada por las Cortes Generales mediante ley orgánica». El precepto transcrito no se sitúa en el ámbito de la garantía constitucional de la provincia (que 
actúa frente a todos los poderes públicos del Estado para preservar una institución existente), sino que contiene una reserva de Ley orgánica para la modificación del concreto statu quo provincial existente en 1978.

La cuestión que nos interesa plantear es si, mediante esa alteración de límites provinciales, puede hacerse desaparecer una provincia concreta. En principio, podría responderse afirmativamente, ya que la garantía constitucional protege la institución provincial en cuanto tal, y no la concreta existencia de cada una de las actuales provincias, en el mismo sentido que la garantía constitucional de los municipios no impide la alteración de los términos municipales, ni la desaparición de algún concreto municipio. Más complejo sería el caso en el que se pretendieran fusionar todas las provincias de una misma Comunidad Autónoma en una sola, para convertir a la Comunidad en uniprovincial y, en definitiva, hacer desaparecer a la entidad local provincial, que quedaría absorbida por las instituciones autonómicas. Ésta es la hipótesis de la que partió la Ley catalana 5/1987, de 4 de abril, sobre régimen provisional de competencias de las Diputaciones provinciales. Esta ley (que viene acompañada por otras de la misma fecha sobre régimen local, y sobre organización comarcal) regula el régimen provisional de las competencias de las Diputaciones provinciales, «mientras no se produzcan las condiciones legales que hagan posible que el Gobierno y la administración de las provincias se integren en la Generalidad, con la consiguiente desaparición de la división de Cataluña en provincias» (art. 1). La Disposición adicional 1. ${ }^{\mathrm{a}}$ concreta dichas condiciones, al instar la alteración de la actual división en cuatro provincias para que, mediante Ley orgánica, se cree una sola provincia en Cataluña, cuyo gobierno y administración correspondería a la Generalidad, al convertirse en Comunidad uniprovincial ${ }^{7}$. Por lo demás, el régimen «provisional» de las Diputaciones provinciales no parece comprender todas aquellas competencias que han de corresponderles según la Ley de Bases del Régimen Local, y se solapa en cuanto a dichas competencias con las que se atribuyen a las comarcas; por todo ello se ha señalado que resulta difícil concluir que las soluciones de la legislación comentada respetan el núcleo esencial de la autonomía provincial que la Constitución garantiza (MARTín RETORTILLO: 1991, p. 120). En definitiva, me parece que la alteración de los límites provinciales puede implicar la desapari-

\footnotetext{
7 Conviene mencionar también que la fusión de las cuatro provincias catalanas se ha intentado efectivamente realizar mediante la presentación de una proposición de Ley orgánica en el Congreso, por parte del Grupo Mixto. Se trata de la proposición de L.O. 122/000037, de creación de la provincia de Cataluña (BOCG, Congreso, VII Legislatura, Serie B, núm. 47-1, de 12 de mayo de 2000), según la cual desaparecerian las actuales Diputaciones Provinciales (cuyas competencias serían asumidas por la Comunidad Autónoma), así como las Subdelegaciones del Gobierno estatal en las provincias.
} 
ción de una concreta provincia en cuanto ello no suponga la desaparición del mismo régimen provincial en el ámbito territorial de una Comunidad Autónoma en el que existía; tal desaparición implicaría en realidad un intento de "esquivar" o eludir la garantía constitucional.

Por último, cabe indicar que la garantía constitucional de la provincia implica un límite a la actuación del legislador, tanto estatal como autonómico. Pero este último cuenta con un límite adicional, teniendo en cuenta el diseño constitucional del reparto de competencias aplicable a la materia. De acuerdo con el artículo 149.1.18. ${ }^{\mathrm{a}}$, corresponden al Estado las bases del régimen jurídico de las Administraciones públicas, que comprenden obviamente las bases del régimen local. Por ello el legislador autonómico debe respetar estas bases estatales en su desarrollo, mientras que el legislador estatal cuenta como único límite con la garantía constitucional. De ahí que, dentro del margen que permite la Constitución, el régimen legal de la provincia pueda variar de forma apreciable, tendiendo a su fortalecimiento o a su debilitación. Eso sí, obviamente el legislador autonómico también ha de tener un margen de actuación, que a su vez puede suponer una estructura, organización y competencias provinciales más o menos fuertes, según los casos.

No es posible en este lugar realizar un análisis exhaustivo de la jurisprudencia constitucional sobre la distribución de competencias en la materia. Pero pueden recordarse algunas ideas básicas:

a) En primer lugar, el Tribunal ha señalado que, como la garantía constitucional es de carácter general y configura un modelo de Estado, corresponde al Estado la fijación de principios o criterios básicos en materia de organización y competencia; aunque ello no puede implicar el establecimiento de un régimen uniforme que no permita opciones diversas (STC 32/1981, F. J. 5).

b) El régimen jurídico de las autonomías locales tiene un «carácter bifronte», que hace imposible calificarlo de forma unívoca como «intracomunitario» o «extracomunitario» (STC 84/1982, de 23 de diciembre, F. J. 4).

c) La competencia estatal deriva esencialmente del artículo 149.1.18. ${ }^{a}$ (bases del régimen jurídico de las Administraciones Públicas). Las «bases» que corresponden al Estado no sólo se refieren a aspectos organizativos o institucionales, sino también a las competencias (STC 214/1989, de 21 de diciembre, F. J. 1). 
d) También son competencia estatal la delimitación de la provincia, su capitalidad y su denominación (STC 385/1993, de 23 de diciembre, F. J. 4).

\section{AUTONOMÍA PROVINCIAL, AUTONOMÍA DE NACIONALIDADES Y REGIONES, Y AUTONOMÍA MUNICIPAL}

Una vez analizados los rasgos esenciales de la autonomía provincial, desde el punto de vista constitucional, conviene comparar dichos elementos con los que pueden predicarse de otros entes dotados constitucionalmente de autonomía. Dejando a un lado las Universidades (art. 27.10 $\mathrm{CE}$ ), que plantean una problemática alejada de la que aquí queremos tratar, nos centraremos en el análisis de las similitudes y diferencias entre la autonomía predicada de las provincias, de las nacionalidades y regiones, y de los municipios.

La autonomía de las provincias, aunque reconocida en el artículo 137 CE del mismo modo que para las CCAA, no es asimilable a la de éstas en su contenido jurídico a la vista del artículo $141 \mathrm{CE}$ y del resto del Título VIII CE principalmente porque: gislar.

- La provincia, a través de su institución representativa, no puede le-

- No existe una capacidad representativa más allá de la de los intereses del vecino en determinados asuntos.

- No tiene un entramado institucional y una separación de funciones comparable a las Comunidades Autónomas. tución.

- No tiene competencias determinadas directamente desde la Consti-

Por todo ello se habla de esta autonomía como de segundo grado, en el marco de la ley o autonomía administrativa. No obstante, su institución representativa esconde un claro componente político en tanto que la toma de decisiones en su marco de competencias se efectúa por los representantes de los vecinos de las provincias, a través de los miembros de la corporación provincial. La determinación de los presidentes que dirigen la actividad ejecutiva y de los diputados delegados de éstos, también se realiza tras un proceso de contenido político incuestionable. 
Por io que se refiere a la comparación de la autonomia provinciai con ia de los municipios, puede afirmarse con carácter general que ambas entidades poseen una naturaleza semejante, aunque la regulación constitucional y legal no es equiparable en uno y otro caso. De la misma manera que existen diferentes consideraciones del hecho provincial y local, el contenido de la autonomía local y provincial, en principio, muestra diferencias, aunque de escaso calado. El sistema de responsabilidad, competencias o la elección de sus miembros, otorga mayor protagonismo al municipio (AJA: 1992, p. 62), pero ni su autonomía ni la garantía de la misma es mayor.

Por tanto, la autonomía provincial tiene la misma naturaleza que la autonomía municipal (que es predominantemente administrativa, aun sin excluir un componente político), y en ambos casos existe una misma garantía constitucional, aunque el desarrollo legal no ha sido idéntico. Pero también conviene destacar las diferencias existentes en la propia regulación constitucional, que pueden apreciarse si se comparan los artículos 140 (municipios) y 141 (provincias) de la Constitución. El propio Tribunal Constitucional ha destacado la «parquedad» de la Constitución al referirse a la provincia (STC 38/1983, de 16 de mayo, caso Ley de Elecciones Locales, F. J. 3); y, en el mismo sentido, se ha dicho que la Constitución pone «menor énfasis en el lenguaje» utilizado para garantizar la autonomía provincial que en el empleado en garantizar el autogobierno de nacionalidades y regiones y la autonomía de los municipios (CLAVERO ARÉVAlO: 1983, p. 2135). Algunos autores (CARBALlEIRA Rivera: 1993, pp. 122 ss.; o PAREJo ALFONSO: 1991, p. 89) han insistido en las diferencias entre la regulación constitucional del municipio y de la provincia. Podemos apuntar algunas de ellas:

a) A diferencia del municipio, la provincia no se configura como entidad local «básica», sino como entidad compuesta por la agrupación de municipios.

b) Se deja entrever el carácter no uniforme de la provincia con la posible creación de otras «agrupaciones de municipios».

c) Mientras que el artículo 140 atribuye al municipio «personalidad jurídica plena», el artículo siguiente afirma que la provincia tiene «personalidad jurídica propia», lo que podría hacer pensar en «un mismo alcance jurídico pero con distinto alcance e intensidad» (CARBALleIRA RIVERA: 1993, p. 125)

d) En comparación con los Ayuntamientos, la descripción de los órganos provinciales y su modo de constitución es menos detallada. No se 
exige la elección de estos órganos por sufragio universal, igual, libre, directo y secreto, sino sólo su carácter representativo.

c) En fin, el artículo 141 no efectúa un reconocimiento del carácter autónomo del ente en su integridad (a diferencia del art. 140, que afirma taxativamente: «la Constitución garantiza la autonomía de los municipios»), sino que se limita a referirse al «gobierno y la administración $a u$ tónoma de las provincias» (art. 141.2), con lo que se alude sólo a una de las manifestaciones esenciales de la autonomía; aunque esta diferencia puede considerarse de matiz, teniendo en cuenta la inequívoca proclamación del artículo 137.

Por otro lado, la configuración constitucional de la provincia como entidad local «determinada por la agrupación de municipios» permite plantearnos en qué medida estamos ante una entidad con sustantividad propia, distinta a la que corresponde a dicha agrupación. Desde luego, la propia Constitución afirma, como hemos visto, la personalidad jurídica propia de la entidad provincial. Desde el punto de vista de su estructura, parece que puede afirmarse su sustantividad, en cuanto formada por un territorio, población y organización que no se definen simplemente como la suma de los de los municipios que la integran (MORELL OCAÑA: 1991, pp. $3.291 \mathrm{ss}$.). Pero la cuestión es más compleja desde la perspectiva de sus intereses y funciones, ya que éstas encuentran su justificación en relación con los municipios. Como ha destacado por ejemplo PAREJO ALFONSO (1991, pp. 96-97), de la configuración constitucional se deduce que entre municipios y provincias existe una diferenciación de las funciones a cumplir dentro de un mismo ámbito de intereses y, consecuentemente, de competencias. Incluso se ha señalado (ORTEGA Álvarez: 1991, p. 471) que existe una única comunidad política local y un interés local común a provincias y municipios.

En fin, ante la existencia de varias instituciones territoriales protegidas mediante una garantía institucional o constitucional, es imprescindible un reparto de competencias y funciones para que puedan atender el mandato constitucional de gestionar sus propios intereses. Sin embargo, la provincia ha sido la entidad más perjudicada por este reparto, de una parte porque el desarrollo legal ha concedido mayores competencias al municipio y de otra porque las Comunidades Autónomas ejercitan las suyas dejando escaso margen al ente local intermedio ${ }^{8}$. El desarrollo legislativo concre-

${ }^{8}$ Sobre las competencias locales, se puede consultar uno de los estudios más completos que sobre el tema se han publicado: J. MIR I BAGO, El sistema español de competencias locales. Ed. Dykinson. Madrid, 1997. 
ta İa autonomía provincial a través de los artículos $1.2,2$ y 9 de la Ley de Bases de Régimen Local, precisando, no obstante, que sus fines son limitados (31.2 LBRL). Con esta conclusión nos quedamos: la diferencia no está en la autonomía o su garantía (aunque sí hay diferencias en su regulación constitucional), pero sí en la opción del legislador de otorgar a la provincia distintos cometidos, como por ejemplo el auxilio a los municipios (ARIMANY Y PICH: 1996, p. 175).

\section{RAZONES A FAVOR DEL MANTENIMIENTO DE LA PROVINCIA Y DE SU INSTITUCIÓN REPRESENTATIVA}

1. La Constitución española, con la redacción actual del artículo 141, no admite ni la desaparición de la provincia, ni de las actuales diputaciones, o cualquier otra institución representativa a su frente que se crease con caracteres similares.

2. En la mayoría de los países de nuestro entorno - incluyendo algunos políticamente descentralizados - existen divisiones supramunicipales e infrarregionales para el cumplimientos de determinadas finalidades; y especialmente en aquellos de gran extensión geográfica (Alemania, Francia, Italia...). Posiblemente, esta generalización obedece a la idea de que, sin una administración intermedia alternativa, el interés público podría resentirse.

3. La constitución de otros entes intermedios alternativos está lejos de ser una realidad en la mayor parte de España. La sustitución de la provincia, por ejemplo, por la comarca (con parecidos caracteres y funciones), podría implicar una menor capacidad de actuación y coordinación por la atomización territorial resultante, además de un considerable aumento del gasto público durante y después de la sustitución institucional. En principio, y salvo motivos que lo justifiquen, si existe una administración supramunicipal, no se entiende por qué hay que desmembrarla para sustituirla por otra

4. También plantea problemas el neocentralismo que ocasionaría la desaparición de las diputaciones y la asunción de su papel por órganos descentralizados de la administración autonómica. Ello ha tenido sentido en la Comunidades Autónomas uniprovinciales pero carecería de fundamento en Comunidades como Castilla-La Mancha o Andalucía, con fuertes diferencias provinciales. No puede olvidarse que la descentralización es un principio que constitucionalmente ha de regir el funcionamiento de la Administración Pública (art. 103.1 CE). 
5. La implantación de entes locales de estatuto legal (mancomunidades, consorcios) con funciones auxiliares y complementarias que son instrumentos para la gestión por su carácter limitado y finalista, no puede conllevar en ningún caso la desaparición de los entes locales que le sirven de sustento ni atribuirse una generalidad de funciones y competencias residuales. Además, no tienen tampoco un carácter representativo.

6. La provincia cumple con una labor de coordinación territorial, auxilio a los pequeños municipios, prestación de servicios de primera necesidad que no podrían tener los municipios por sí solos, e impulsa actuaciones complementarias en temas de competencia municipal, mejorando la gestión local.

7. La provincia y su diputación, al menos en una parte de España, gozan de un considerable arraigo, si bien es verdad que la provisión, organización y funcionamiento de las diputaciones es desconocida por la inmensa mayoría de los ciudadanos.

8. Todos los argumentos jurídicos que pudieran justificar un cambio esencial en la provincia (como, por ejemplo, la suspensión de la garantía constitucional que la protege) tropezarían contra el muro de la necesaria reforma del Título VIII CE. ¿Alguien cree posible modificar este Título sin abordar otros problemas de mayor calado, como la reforma del Senado? ¿Es conveniente, política, lógica y racionalmente, plantear cualquier alteración en los artículos constitucionales referentes al territorio, ante el principal problema (el cuestionamiento del modelo territorial de Estado, en algunos casos a través del terrorismo) de nuestro país, que tiene su origen en una reivindicación territorial independentista?

En resumen, admitiendo excepciones (comarcas en Cataluña, por ejemplo), hoy por hoy no es lógico apostar por una desaparición generalizada de la provincia ni de su administración en todo el territorio nacional.

\section{ARGUMENTOS CONTRA LA NECESIDAD DE LA PROVINCIA COMO ENTIDAD LOCAL}

Las consideraciones realizadas en la primera parte de este trabajo ponen de manifiesto la existencia de una garantía constitucional de la provincia (considerada ahora como entidad local), que, a pesar de todas las diferencias que puedan señalarse respecto a la autonomía de nacionalidades y regiones, por un lado, o de municipios, por otro, lo cierto es que sin 
duda alguna impide su supresión o desaparición total. Reconocida por tanto la garantía constitucional de la provincia, no puede defenderse jurídicamente su supresión dentro del actual marco constitucional. Pero lo cierto es que el jurista puede realizar también propuestas de futuro, teniendo en cuenta argumentos sobre el funcionamiento real de las instituciones y su utilidad, así como otros basados en una visión sistemática y armónica de las diferentes entidades territoriales dotadas de competencias. Me parece que no está de más analizar la conveniencia o utilidad de la garantía constitucional de la provincia, situándonos ya en el siglo XXI, y no en 1978. Como ha apuntado GARRIDO MAYOL (1991-92, p. 117), la configuración del Senado y la cuestión provincial son causa para que se insista en la reforma de la Constitución.

Por otro lado, conviene aclarar que los argumentos que se van a exponer no están encaminados a justificar la inutilidad de la provincia en todas sus dimensiones, sino específicamente a afirmar la inconveniencia de establecer la provincia como entidad local necesaria u obligatoria en todo caso. En cambio, puede reconocerse la utilidad de la provincia como división territorial para el cumplimiento de las actividades del Estado, aspecto éste al que puede unirse en algunas Comunidades, con igual o mayor importancia, el de división territorial para el cumplimiento de la actividad propia de la Comunidad Autónoma. Por lo que se refiere a su utilización como circunscripción electoral, puede ser inadecuada en el caso del Senado, y dudosa en el caso del Congreso de los Diputados 9 .

En fin, también hay que precisar que aquí no se defenderá tanto la conveniencia de suprimir obligatoriamente la provincia como entidad local en toda España, como la de hacer desaparecer la garantía constitucional de la misma, por considerarla una entidad no necesaria o imprescindible desde el punto de vista global del Estado, aunque podría configurarse como una entidad constitucionalmente posible, y seguir existiendo como tal en algunas Comunidades Autónomas. Y ello porque la realidad y la situación de la provincia en España no parece en absoluto homogénea. Obviamente, el problema en examen no se plantea hoy en el caso de las

\footnotetext{
${ }^{9}$ No podemos extendernos en este punto, que excede el objeto de este trabajo. Pero sí podemos apuntar que parece claro que el Senado como Cámara de representación territorial debería en la actualidad representar, exclusiva o muy primordialmente, a los territorios dotados de autonomía politica y legislativa, esto es, a las Comunidades Autónomas. En cuanto al Congreso, como Cámara representante de la población, si bien es cierto que no resulta necesariamente inadecuada la circunscripción provincial, también debe reconocerse que nada impediría (obviamente, desde el punto de vista político y de la organización institucional del Estado, dejando a un lado ahora el mandato constitucional del art. 68.2) el establecimiento de otro tipo de circunscripción, como por ejemplo la autonómica.
} 
Comunidades Autónomas uniprovinciales, en el que los órganos y competencias provinciales han sido absorbidos por los autonómicos. Entre las restantes, como veremos, ni el arraigo o tradición de la provincia ni su adecuación a la realidad pueden considerarse iguales en todos los territorios.

Hechas las anteriores precisiones, podemos pasar a sistematizar los argumentos más sólidos en contra de la necesidad de la provincia como entidad local:

1) La provincia contribuye a la multiplicación de entidades diversas que poseen competencias sobre el mismo territorio. Actualmente, y como mínimo, sobre cualquier parte del territorio español despliegan competencias cinco entidades: las Instituciones Europeas, el Estado, la Comunidad Autónoma, la provincia y el municipio. Y a éstas hay que añadir en algunos casos agrupaciones de municipios de ámbito infraprovincial, como las comarcas, y de ámbito inframunicipal, como las entidades locales menores. Ello posee varios efectos negativos: en primer lugar, aumenta las dificultades para la delimitación de competencias y funciones en determinadas materias, favoreciéndose los conflictos de competencias. En segundo lugar, la multiplicación de Administraciones aumenta la complejidad burocrática y provoca en algunos casos la confusión y desorientación de los ciudadanos.

No se trata obviamente de culpar de modo exclusivo a la provincia de esta multiplicación de instancias y de la creciente complejidad administrativa y burocrática. Pero parece que ante una situación así la existencia de cualquier nivel administrativo debe aparecer especialmente justificada en su necesidad o conveniencia. Por otro lado, es cierto que el problema podría mitigarse mediante una mejor coordinación y organización administrativa, pero en todo caso la complejidad aumenta, lo que sólo parece justificado en función de la utilidad de las entidades. Y dicha utilidad es dificil de justificar cuando existen diversos niveles administrativos que poseen parecidas funciones y ejercen similares competencias sobre un territorio, lo que es especialmente manifiesto allí donde existen otras agrupaciones de municipios de ámbito supramunicipal.

2) Por tanto, la justificación de la provincia podría venir dada por la utilidad de sus funciones, unida a la necesidad de que las mismas se desempeñen por la entidad provincial. Pero no puede afirmarse con carácter general que dichas premisas se cumplan. La actual regulación de la provincia (en concreto, art. 31.2 de la Ley de Bases del Régimen Local) señala como fines propios la garantía de los principios de solidaridad y 
equilibrio intermunicipaies, y en concreto: asegurar ia prestación integrai y adecuada en la totalidad del territorio provincial de los servicios de competencia municipal, y participar en la coordinación de la Administración local con la autonómica y estatal. Y el artículo 36.1 LBRL establece las competencias propias de las Diputaciones, que en definitiva vienen a desarrollar los fines antes mencionados: coordinación de servicios municipales entre sí para garantizar la prestación integral y adecuada de servicios municipales; asistencia y cooperación jurídica, económica y técnica a los municipios; prestación de servicios públicos de carácter supramunicipal y, en su caso, supracomarcal; $y$, en general, el fomento y administración de los intereses peculiares de la provincia. Por cierto, ninguno de los dos artículos mencionados ha sido modificado por la reciente reforma de la LBRL por Ley 11/1999, que en este aspecto modifica sobre todo cuestiones de organización y funcionamiento, pero mantiene las funciones y competencias propias de la provincia, cuyo papel en el sistema de distribución territorial del poder no se ve alterado.

En suma, las funciones actuales de las provincias se centran en tres ámbitos: a) la asistencia y cooperación con los municipios, asegurando la prestación de los servicios y competencias de éstos (auxilio de municipios); b) la prestación de servicios públicos supramunicipales o supracomarcales, así como el fomento y administración de los intereses peculiares de la provincia; y c) la coordinación de la Administración local con la autonómica y estatal. Esta última función no justifica su existencia, pues la necesidad de coordinación es precisamente fruto de la complejidad y cantidad de instancias administrativas (que se reduciría con la supresión de la provincia); $y$, por lo demás, dicha coordinación podría llevarse a cabo por otras entidades (como las comarcas o las Comunidades Autónomas). La existencia de una entidad autónoma no parece pueda encontrar justificación en la función de coordinar otras instancias (el mismo argumento podría utilizarse para crear nuevas entidades para coordinar municipios y provincias, o provincias y Comunidades Autónomas, por ejemplo).

En cuanto a la prestación de servicios públicos supramunicipales y supracomarcales, no parece imprescindible que la misma deba llevarse a cabo precisamente por una entidad local de ámbito provincial, ya que igualmente podría desempeñarse por agrupaciones infraprovinciales (en el caso de los servicios supramunicipales) o por la Administración autonómica, tanto en el caso de servicios supramunicipales como supracomarcales. Y por lo que se refiere al fomento y administración de los intereses provinciales, creo que dicha función no justifica la existencia de la entidad provincial, sino que es consecuencia de la misma; en realidad, di- 
chos intereses rara vez aparecen de una forma autónoma a los intereses propios de los municipios. Es dificil hablar de unos «intereses provinciales», siendo más realista pensar en los intereses de los municipios, cuya agrupación constituye la provincia, aunque también son admisibles otras agrupaciones de ámbito territorial diferente.

En realidad, parece que la función esencial de la entidad local provincial radica en el auxilio a los municipios, supliendo en su caso sus dificultades para la prestación de los servicios mínimos exigidos por la ley. Esta función tiene incuestionablemente una importancia capital, pero (al igual que sucede con la prestación de servicios supramunicipales o supracomarcales) tampoco se entiende por qué ha de venir realizada necesariamente por las Diputaciones Provinciales, y no por otras entidades de ámbito inferior, o incluso por las propias Comunidades Autónomas, según los casos (utilizando, cuando ello sea preciso, una organización autonómica basada en una Administración desconcentrada que podría en su caso coincidir con el ámbito territorial provincial). De hecho, la jurisprudencia constitucional, que por un lado ha reconocido que el núcleo de la actividad provincial es el apoyo a los municipios, ha admitido sin embargo - aunque sólo en el caso de Cataluña - que el «peso» principal de la función de cooperación a las obras y servicios municipales recaiga en la Comunidad Autónoma, cuyas competencias en este ámbito exceden de la simple «coordinación» a que se refiere el artículo 36.2.a) LBRL (véase la ya citada STC 109/1998).

3) El «arraigo» de la organización provincial en España no puede afirmarse con carácter general, y desde luego debe ser muy precisado. Aunque pudieran señalarse numerosos matices, y las opiniones no son coincidentes ${ }^{10}$, creemos que con carácter general pueden distinguirse diversos supuestos (dejando de lado las Comunidades Autónomas uniprovinciales y las insulares, con evidentes características propias):

a) El País Vasco, con entidades provinciales muy reforzadas, como consecuencia de su fuerte tradición histórica, muy anterior desde luego a la división provincial del siglo XIX.

b) Comunidades donde la provincia ha tenido un arraigo menor, y en las que con frecuencia existe también una división territorial de ámbito inferior a la provincia (comarcas...): Cataluña, Valencia, Galicia.

\footnotetext{
${ }^{10}$ En sentido diferente al aqui expuesto, véase, por ejemplo, A. Guaita Martorell, «Las provincias españolas a partir de la Constitución de 1978», en Revista de Administración Pública, núm. 94, 1981 , p. 48, quien afirmaba que el sentimiento generalizado era más bien provincialista, con la única excepción de Cataluña, y «un pequeño movimiento y foco antiprovincial» en Valencia.
} 
c) Comunidades en las que, con los matices que pudieran señalarse, la división provincial del siglo XIX parece haber arraigado más: Castilla y León, Castilla-La Mancha, Andalucía y, en cierta medida, Extremadura y Aragón. Con todo, dicho arraigo no excluye la existencia en estos ámbitos de comarcas con gran tradición (por ejemplo, La Mancha, La Alcarria), y que en algún caso cuentan con una incipiente organización comarcal (El Bierzo).

Por tanto, el «arraigo» de la organización provincial sólo puede afirmarse en algunas partes del territorio nacional, lo que no justificaría la imposición de la provincia en toda España. Pero sobre todo debe señalarse que lo que parece haberse implantado con arraigo es la provincia como división del territorio (cuya desaparición no se defiende aquí), y no tanto la Diputación Provincial como órgano de gobierno de la entidad autónoma.

4) En general - y aunque no disponemos de datos sociológicos precisos - parece que el ciudadano no percibe a la Diputación Provincial como una entidad cercana, próxima a sus intereses, y en definitiva útil, desconociendo en muchos casos sus competencias y fines; y ello a pesar de que geográficamente cuenta con ventaja respecto a la Comunidad Autónoma o el Estado. A ello contribuye probablemente la elección de los miembros de estas Corporaciones de forma indirecta, pero también una cierta confusión de los intereses provinciales con los municipales.

5) La situación ha cambiado notoriamente desde 1978 a la actualidad. Al aprobarse la Constitución el «mapa autonómico» estaba por cerrar (e incluso podía no haberse cerrado), mientras que las provincias estaban implantadas y eran ampliamente conocidas. Como ha destacado GARCÍA DE ENTERRÍA, no resultaba adecuado en estas condiciones retocar ni suprimir una estructura básica como venía siendo la provincia durante los últimos ciento cincuenta años de nuestra historia; si la situación hubiera sido diferente, y se hubiera previsto en el texto constitucional una estructura territorial ordenada sobre entidades políticas miembros del Estado compuesto, "podría haberse dejado la subsistencia de la provincia, o la definición de su posición exacta dentro de dicha estructura, a la determinación de dichas entidades políticas, aquí Comunidades Autónomas» (GARCÍA DE ENTERRÍA: 1991, p. 6).

El proceso seguido desde 1978 por ambas entidades ha sido inverso: las Comunidades Autónomas se han afianzado en su organización y funcionamiento, y en la conciencia de la población, incluso allí donde carecían de la más mínima tradición o «conciencia regional». Las provincias, en cambio, 
han ido perdiendo importancia de manera casi generalizada, en favor de las propias Comunidades o de las comarcas. Este proceso puede advertirse incluso en Comunidades que como tales carecían de toda tradición histórica, y que comprenden territorios en los que la provincia tenía un considerable arraigo (que por lo demás tampoco ha desaparecido) ${ }^{11}$.

6) En fin, los argumentos basados en el Derecho comparado deben tomarse con toda la precaución que impone la diferente realidad y situación de cada país ${ }^{12}$. Se trata de buscar la organización más adecuada en España ( 0 , más exactamente, en cada una de las Comunidades que comprende el territorio nacional), y no de justificar una institución por la existencia de otras más o menos similares en Estados de nuestro entorno. Por lo demás, las entidades locales supramunicipales que en ocasiones se utilizan como modelo o argumento para justificar la necesidad de una organización provincial no siempre son equiparables en su estructura, ni desde luego en su ámbito territorial, a nuestras provincias.

En suma, desde la perspectiva actual, es algo artificial la extensión a la provincia de la garantía constitucional. Sus funciones podrían estar asumidas por otras entidades de ámbito supramunicipal (comarcas, etc.), o por las Comunidades Autónomas, mediante una estructura administrativa desconcentrada cuando ello fuera necesario, aunque ambas opciones serían compatibles. En concreto, la comarca cuenta con algunas ventajas sobre la provincia, que hacen que pueda resultar una entidad más adecua$\mathrm{da}$, al menos en algunos territorios: se trata de un ámbito territorial más idóneo para prestación de servicios y gestión de asuntos comunes intermunicipales, por su mayor proximidad con el administrado; y, por otra parte, está desprovista de la carga política que para algunos tiene la provincia (en este sentido, por ejemplo, GARRIDO MAYOL: 1991-92, p. 118).

Lo dicho no significa que necesariamente la entidad local provincial hubiera de desaparecer de todo el territorio nacional, pero lo que hoy ca-

11 Un claro ejemplo podría encontrarse en Castilla-La Mancha, con la creación de la Universidad regional, o la fusión de las Cajas de Ahorro, que probablemente se produzca también en otras $\mathrm{Co}_{0}$ munidades (aunque en ambos casos, y por razones diversas, haya quedado fuera Guadalajara). En la misma línea es significativa la reforma del Estatuto de Autonomía de esta misma Comunidad producida en 1997, que sustituyó, en el artículo 1.1, la mención a las cinco provincias como sujeto que accedia a la autonomía, por la referencia directa a «Castilla-La Mancha»; al tiempo que, en la definición del territorio regional (art. 2.1), se sustituía la expresión «el comprendido en las provincias de Albacete, etc.», por "corresponde al de los municipios que integran las provincias...»

12 Un repaso al Derecho comparado en la materia puede verse en los últimos cuatro capitulos de la obra colectiva La provincia en el sistema constitucional, dir. R. GÓMEZ-FERRER MORANT, Diputació de Barcelona/Civitas, Madrid, 1991, pp. 515 ss., donde se analizan la provincia italiana, el departamento francés, el condado inglés y norteamericano, y las agrupaciones de municipios en Alemania. 
rece de sentido es su imposición como órgano necesario desde la propia Constitución. Como ha apuntado RIVERO YSERN (1993, p. 153), la actual configuración de la provincia se ha revelado como un elemento, por su rigidez, distorsionante en el proceso de construcción y consolidación del nuevo modelo de organización territorial del Estado.

Pero lo cierto es que en tanto en cuanto la Constitución no se reforme, o si no se opta por esta reforma, tampoco resulta justificado mantener a las Diputaciones provinciales como órganos más o menos inservibles y alejados de los ciudadanos, que incluso distorsionan el sistema de distribución del poder. Y me parece que, en la actual situación, las Diputaciones podrían encontrar, al menos en algunos casos, una utilidad o justificación por dos vías: descentralización de competencias y funciones autonómicas, y auxilio a los municipios. En el primer ámbito, pueden resultar muy adecuadas, al menos en algunas Comunidades, las fórmulas previstas en el artículo 37.1 LBRL: delegación de competencias de las Comunidades Autónomas en las Diputaciones, y gestión ordinaria por parte de éstas de los servicios propios de las Comunidades. Incluso podría ser positivo un cierto refuerzo de las Diputaciones allí donde se juzgue conveniente, mediante la gestión de competencias autonómicas para evitar una duplicación con la Administración de la Comunidad Autónoma. Como ha señalado BASSOLS COMA (1996, p. 470), la provincia encontrará su papel institucional propio en el Estado de las autonomías redefiniendo, en su escalón propio, sus funciones al servicio de las Comunidades Autónomas. En el segundo ámbito antes mencionado (cooperación y auxilio a los municipios), la utilidad de las Diputaciones puede encontrarse en la prestación de servicios esenciales en pequeños municipios, así como en una labor de promoción, estudio o asesoramiento en las materias que afectan a la vida local. Todo ello podría conllevar un mayor acercamiento al ciudadano, que permita que éste reconozca a las Diputaciones, en tanto tengan que existir, como una entidad útil.

Ahora bien, ni siquiera estas soluciones pueden propugnarse con carácter general, ya que la situación es muy diferente entre unas y otras Comunidades, y es preciso tener en cuenta factores como la existencia o no de otras entidades locales supramunicipales, la organización más o menos desconcentrada de la Administración autonómica, la extensión del territorio y el número de provincias, la población... La gran heterogeneidad existente en los diversos territorios de España en relación con la provincia imposibilita soluciones uniformes en todo el Estado ${ }^{13}$. Conviene por

${ }^{13}$ Un completo análisis de la situación de la provincia en las diversas Comunidades Autónomas puede encontrarse en la obra colectiva La provincia en el Estado de las Autonomias, Diputació de 
tanto respetar el mayor margen posible de organización a cada Comunidad Autónoma. Se ha destacado que la Constitución ha atendido a la situación histórica de diversidad, permitiendo diversas tipologías o regímenes provinciales, cuyos «extremos» serían el del País Vasco y el catalán (MORELL OCAÑA: 1988, p. 695); pero hay que reconocer que la regulación constitucional y la legislación básica aprobada por el legislador estatal no dejan tampoco un excesivo margen al legislador autonómico para adaptar sus Diputaciones a su concreta realidad. Ello provoca que, sobre todo allí donde existen entidades supramunicipales como las comarcas, sea muy dificil evitar la duplicación de competencias y funciones entre éstas y las provincias, lo que es tan innecesario como inconveniente. Pero en todo caso se hace imprescindible una mayor coordinación entre Administraciones, que evite que éstas actúen de manera aislada o desconociendo la existencia y competencias propias de las demás.

\section{BIBLIOGRAFÍA CITADA}

ARIMANI LAMOGLIA, E. y PICH FRUTOS, E., «Las diputaciones provinciales y su función como entes de auxilio a los municipios. Confirmación Jurisprudencial. Comentario a la STS de 29 de noviembre de 1995», En Revista de Administración Pública, núm. 140, mayo- agosto de 1996.

BARAS, M. y Botella, J., El sistema electoral, Tecnos, 1996.

BASSOls COMA, M., «Las Diputaciones Provinciales a los diez años de la Ley reguladora de las Bases del Régimen Local: experiencias y perspectivas», en VV.AA., La provincia en el Estado de las autonomías, Diputació de Barcelona/Marcial Pons, Madrid, 1996.

Barcelona/Marcial Pons, Madrid, 1996. Sobre la relación entre provincias y Comunidades Autónomas, además de parte de la bibliografia ya citada, por ejemplo, P. EsCRIBANo Collado y J. L. Rivero YSERN, «La provincia en los Estatutos de Autonomía y en la LOAPA (a propósito del papel de las provincias en la Administración de las Comunidades Autónomas)", en Revista de Administración Pública, núm. 104, 1984; V. M. Escuin PALOP, «La delegación de competencias de las Comunidades Autónomas a las Diputaciones Provinciales», en Revista Vasca de Administración Pública, núm. 10, vol. I, 1984; P. Garcia-Escudero Márquez y B. Pendás Garcia, «La provincia como entidad local en el Estado de las autonomías", en VV.AA., Organización territorial del Estado (Administración local), Instituto de Estudios Fiscales, vol. II, Madrid, 1985; J. L. MarTínez LóPEz-MuNiz, «Provincias y Comunidades Autónomas pluriprovinciales: problemas de articulación», en VV.AA., Organización territorial del Estado (Administración Local), Instituto de Estudios Fiscales, vol. III, Madrid, 1985. 
BoIX REIG, V., «Significación de la provincia en la distribución territorial del poder diseñada por la Constitución española», en Revista de Administración Pública, núm. 115, 1988.

BURGUEÑo, J., Geografia política de la España Constitucional, Centro de Estudios Constitucionales, Madrid, 1996.

CARBALleIRA RIVERA, M. T., La provincia en el sistema autonómico español, Universidade de Santiago de Compostela/Marcial Pons, Madrid, 1993.

Clavero ARÉVALO, M., «La provincia ante una encrucijada histórica», en Revista de Administración Pública, núm. 100-102.

DE CASTRO, C., La revolución liberal y los municipios españoles, Alianza Universidad, Madrid, 1979.

ESCRIBANO COLLADO, P. y RIVERO YSERN, J. L., «La provincia en los Estatutos de Autonomía y en la LOAPA (a propósito del papel de las provincias en la Administración de las Comunidades Autónomas)», en Revista de Administración Pública, núm. 104, 1984.

ESCUÍN PALOP, V. M., «La delegación de competencias de las Comunidades Autónomas a las Diputaciones Provinciales"), en Revista Vasca de Administración Pública, núm. 10, vol. I, 1984.

ESQUERDA I ROSET, J. M., et alii, «La provincia», en Autonomies, núm. 5, 1986.

ESTEVE PARDO, J., «Garantía institucional y/o función constitucional en las bases del régimen local», en Revista Española de Derecho Constitucional, núm. 31, 1991.

GARCÍA DE ENTERRÍA, E., «La provincia en la Constitución», en Gómez-Ferrer Morant (dir.), La provincia en el sistema constitucional. Diputació de Barcelona/Civitas, Madrid, 1991, pp. 5 ss.

GARCIA MORILLO, J., La configuración constitucional de la autonomía local, Diputació de Barcelona/Marcial Pons, Madrid, 1998.

GARCÍA ROCA, J., «El concepto actual de autonomía local según el bloque de la constitucionalidad», en Revista de Estudios de la Administración Local y Autonómica, núm. 282, enero-abril 2000. 
GARCÍA-ESCUDERo MÁRQUEZ, P. y PENDÁs GARCÍA, B., «La provincia como entidad local en el Estado de las autonomías», en VV. AA., Organización territorial del Estado (Administración local), Instituto de Estudios Fiscales, vol. II, Madrid, 1985.

GARRIDO MAYOL, V., «La provincia en el Estado autonómico», en $R e$ vista de la Facultad de Derecho de la Universidad Complutense de Madrid, núm. 80, 1991-1992.

GÓMEZ-FERRER MORANT (dir.), La provincia en el sistema constitucional. Diputació de Barcelona/Civitas, Madrid, 1991.

GUAITA MARTORELL, A., «Las provincias españolas a partir de la Constitución de 1978», en Revista de Administración Pública, núm. 94, 1981.

LÓPEZ AGUILAR, J. F., «La forma de gobierno canaria», en VV.AA., Formas de Gobierno y sistemas electorales, coordinadores: Gerardo Ruiz-Rico y Silvio Gambino. Ed. Tirant lo Blanch. Valencia, 1997.

MARTíN-RETORTILlo BAQUER, S., «Presente y futuro de las Diputaciones Provinciales», en Revista Española de Derecho Administrativo, núm. 39, 1983.

MARTín-RETORTILlo BAQUER, S., La provincia. Pasado, presente y futuro, Civitas, Madrid, 1991.

MARTÍNEZ LÓPEZ-MUÑIZ, J. L., «Provincias y Comunidades Autónomas pluriprovinciales: problemas de articulación», en VV.AA., Organización territorial del Estado (Administración Local), Instituto de Estudios Fiscales, vol. III, Madrid, 1985.

MORELL OCAÑA, L., «La provincia en la configuración y ordenación territorial de las Comunidades Autónomas», en Revista Española de Derecho Administrativo, núm. 31, 1981.

MORELL OCAÑA, L., «Raíces históricas de la concepción constitucional de la provincia», en Revista Española de Derecho Administrativo, núm. 42, 1984.

MORELL OCAÑA, L., El régimen local español, Civitas, Madrid, tomo I, 1988 (1988 a). 
MORELl OCAÑA, L., «Las provincias», en obra dirigida por Muñoz Machado Tratado de Derecho Municipal, vol. I. Civitas. Madrid, 1988 (1988 b).

MORELL OCAÑA, L., «La concepción constitucional de la provincia como entidad local», en Estudios sobre la Constitución española. Homenaje al Profesor Eduardo Garcia de Enterría, coord. S. Martín-Retortillo, Civitas, tomo IV, Madrid, 1991.

ORDUÑa REBOLLO, E., «La Constitución de 1812 y las diputaciones», en Carta Local. FEMP, octubre de 1998.

Ortega Álvarez, L., «El nuevo papel de las Diputaciones Provinciales», en Revista de Estudios de la Administración Local y Autonómica, núm. 251, 1991.

PAREJO Alfonso, L., Garantia institucional y autonomías locales, Instituto de Estudios de Administración Local, Madrid, 1981.

PAREJO ALFONSO, L., «La provincia como entidad local determinada por la agrupación de municipios; fines básicos y competencias mínimas», en Gómez-Ferrer Morant (dir.), La provincia en el sistema constitucional. Diputació de Barcelona/Civitas, Madrid, 1991.

RIVERo YSERN, J. L., Manual de Derecho local, Civitas, Madrid, 1993.

Santana Molina, M., La Diputación Provincial en la España decimonónica, ed. INAP, Madrid, 1989.

VV.AA., Organización territorial del Estado (Administración Local), Instituto de Estudios Fiscales, Madrid, 3 vols., 1985.

VV.AA., La provincia en el Estado de las autonomias, Diputació de Barcelona/Marcial Pons, Madrid, 1996. 
REALA-2000, núm. 284. DIAZ REVORIO, FRANCISCO JAVIER. LA PROVINCIA Y LA DIPUTACI...

REALA-2000, núm. 284. DIAZ REVORIO, FRANCISCO JAVIER. LA PROVINCIA Y LA DIPUTACI... 